\title{
Biosynthesis of Silver Nanoparticles from Morinda tinctoria Leaf Extract and their Larvicidal Activity against Aedes aegypti Linnaeus 1762
}

Ramesh Kumar $\mathbf{K}^{1 *}$, Nattuthurai ${ }^{1}$, Gopinath $\mathbf{P}^{1}$ and Mariappan $\mathbf{T}^{\mathbf{2}}$

${ }^{1}$ Post Graduate and Research Department of Zoology, Vivekananda College, Tiruvedakam West, Madurai-625234, India

${ }^{2}$ Centre for Research in Medical Entomology (CRME), 4, Sarojini Street, Chinna chokkikulam, Madurai, India

\begin{abstract}
Mosquitoes include the major vector population for the transmission of many diseases for global mortality and morbidity with increased resistance to common insecticides. Aedes aegypti vector of dengue is spread into many parts of the globe, a study intend to investigate the efficacy of the leaf extract of Morinda tinctoria and silver nanoparticles (AgNps) synthesized using M. tinctoria against the third instar larvae of Ae. aegypti. AgNps were synthesized from leaf extract of $M$. tinctoria and its effects against $3^{\text {rd }}$ instar larvae of Ae. aegypti were evaluated in the laboratory. The produced nanoparticles were subjected to different analysis include UV-Vis spectroscopy, Atomic Force Microscopy (AFM) and Fourier Transform Infrared Radiation (FTIR) spectroscopy. Both The leaf extract and the synthesized AgNps were tested against the $3^{\text {rd }}$ instar larvae of $A e$. aegypti and the recorded $50 \%$ lethal concentration $\left(\mathrm{LC}_{50}\right)$ were 11.716 $\mathrm{ppm}$ and $3.631 \mathrm{ppm}$ respectively. The results recorded from UV-Vis spectroscopy, AFM and FTIR Spectroscopy support the biosynthesis and characterization of AgNps. The results suggested that the leaf extract of $M$. tinctoria and synthesis of AgNps have the potential to be used as an ideal eco-friendly approach towards the control of Ae. aegypti in the field.
\end{abstract}

Keywords: Morinda tinctoria; Ae. Aegypti; UV-Vis spectroscopy; Atomic force microscopy; Fourier transform infrared spectroscopy

\section{Introduction}

Mosquitoes are the principal vector of many vector- borne diseases (VBDs) affecting human beings and other animals lead to cause thousands of deaths per year. India reports 1.48 million malaria cases and about 173 deaths: 1.4 million suspected and 11,985 confirmed chikungunya cases; 5,000 Japanese encephalitis (JE) cases and approximately 1,000 deaths; 383 dengue cases and 6 deaths during 2006 and 2007 [1]. Mosquito - borne diseases have an economic impact, including loss in commercial and labour output particularly in countries with tropical and subtropical climates; however no parts of the world is free from VBD.

Aedes aegypti, vector of dengue is widely distributed in the tropical and subtropical zones. Dengue fever incidence has increased fourfold since 1970 and nearly half the world's population, 1.5 billion people lived in regions where the estimated risk of dengue transmission was greater than $50 \%$ [2]. Though yellow fever has been reasonably brought under control with its vaccine, however no vaccine is available for dengue. The only way of decreasing the incidence of this disease is the eradication of Ae. aegypti [3]. Over 2.5 billion people over $40 \%$ of the world's population are now at risk due to dengue. WHO currently estimates there may be 50 - 100 million dengue infections reported worldwide every year [4].

Insecticide application although highly efficacious against the target species, vector control is facing a threat due to the development of resistance to chemical insecticide resulting in rebounding vectorial capacity [5]. Essential oil or extract from plant may be an alternative source of mosquito control agents, since they constitute a rich source of bioactive compounds that are biodegradable into non-toxic products and potentially suitable for use to control mosquitoes. Plant extract in general have been recognized as an important natural resource of insecticides [6,7]. Applications of phytochemical in mosquito control were in use since the 1920s [8], but the discovery of synthetic insecticides such as DDT in 1939 side tracked the application of phytochemical in mosquito control programme. After facing several problems due to injudicious and over application of synthetic insecticides in nature, refocus on phytochemical that are easily biodegradable and have no illeffects on non-target organisms was appreciated. Since then, the search for new bioactive compounds from the plant kingdom and an effort to determine its structure and commercial production has been initiated. At present phytochemical make upto 1 per cent of world's pesticide market [9].

Botanicals are basically secondary metabolites that serve as a means of defense mechanism of the plants to withstand the continuous selection pressure from herbivore predators and other environmental factors. Several groups of phytochemical such as alkaloids, steroids, terpenoids, essential oils and phenolics from different plants have been reported previously for their insecticidal activities [10]. Insecticidal effects of plant extracts vary not only based on plant species and its parts used, mosquito species, and geographical varieties but also due to extraction methodology adopted and the polarity of the solvents used during extraction. A wide selection of plants from herbs, shrubs and large trees was used for extraction of mosquito toxins. Phytochemical were extracted either from the whole body of little herbs or from various parts like fruits, leaves, stems, barks, roots, etc., of larger plants or trees. In all cases where the most toxic substances were concentrated upon, found and extracted for mosquito control.

More than 2000 plant species have been known to produce chemical factors and metabolites of value in pest control programmes. Members of the plant families- Solanaceae, Asteraceae, Cladophoraceae, Labiatae,

*Corresponding author: Ramesh Kumar K, Post Graduate and Research Department of Zoology, Vivekananda College, Tiruvedakam West, Madurai-625234 India, Tel: 04543 -258234; E-mail: pnkramesh@gmail.com

Received October 06, 2014; Accepted October 24, 2014; Published November 02, 2014

Citation: Ramesh Kumar K, Nattuthurai, Gopinath P, Mariappan T (2014) Biosynthesis of Silver Nanoparticles from Morinda tinctoria Leaf Extract and their Larvicidal Activity against Aedes aegypti Linnaeus 1762. J Nanomed Nanotechnol 5: 242. doi: 10.4172/2157-7439.1000242

Copyright: (c) 2014 Ramesh Kumar K, et al. This is an open-access article distributed under the terms of the Creative Commons Attribution License, which permits unrestricted use, distribution, and reproduction in any medium, provided the original author and source are credited. 
Citation: Ramesh Kumar K, Nattuthurai, Gopinath P, Mariappan T (2014) Biosynthesis of Silver Nanoparticles from Morinda tinctoria Leaf Extract and their Larvicidal Activity against Aedes aegypti Linnaeus 1762. J Nanomed Nanotechnol 5: 242. doi: 10.4172/2157-7439.1000242

Page 2 of 5

Miliaceae, Oocystaceae and Rutaceae have various types of larval, adulticidal or repellent activities against different species of mosquitoes [10].

In addition to the direct use of phytoextracts, in recent days, biosynthesized gain momentum as biocontrol agents against mosquitoes and microbes. Under these circumstances, improvised methods using the biologically synthesized AgNps are emerging as one of the fastest growing material due to their unique physical, chemical and biological properties, small size and high specific surface area [11].

India being rich in herbs can utilize its herbs for such purpose, plants not only being pesticides/insecticides it can also act as an effective antimicrobial, antifungal, ant parasitic and anti-malarial agents. Thus it has been expensively exploited for these properties; here in the present study we have used the plant source Morinda tinctoria and AgNps as larvicidal against Ae. aegypti with following objectives:

- Biosynthesis of AgNps using M. tinctoria.

- Characterization of the synthesized nanoparticles.

- Comparing the efficacy of the leaf extract of M. tinctoria and AgNps synthesized using to same plant material against $3^{\text {rd }}$ instar larvae of Ae. aegypti

\section{Materials and Methods}

\section{Plant collection}

Morinda tinctoria was collected from Vivekananda College campus (Figure 1). The Morinda was collected and washed several times with tap water to remove dust and soil. The leaves were removed and it was washed with tap water and rinsed with distilled water. The cleaned leaf material was dried in shade at room temperature and stored for further use.

\section{Preparation of acetone extract}

The dried leaves were used to prepare the extract adopting the standard simplex centroid experiment design procedure described elsewhere [12]. 25 gms of the dried material was powdered mechanically using electrical stainless steel blender. The powder was mixed with 250 $\mathrm{ml}$ acetone and boiled (boiling point range $55.5^{\circ}-56.5^{\circ} \mathrm{C}$ ) in Soxhlet apparatus for $8 \mathrm{hrs}$. The extract collected was stored at $4^{\circ} \mathrm{C}$ for further use.

\section{Silver nanoparticles (AgNps)}

Synthesis and purification: For synthesis of AgNps, $10 \mathrm{ml}$ acetone extract of $M$. tinctoria was added to $90 \mathrm{ml} 1 \mathrm{mM}$ solution of silver nitrate in $250 \mathrm{ml}$ conical flask and kept at room temperature for $1 \mathrm{hr}$. The primary detection of synthesized AgNps was carried out in the

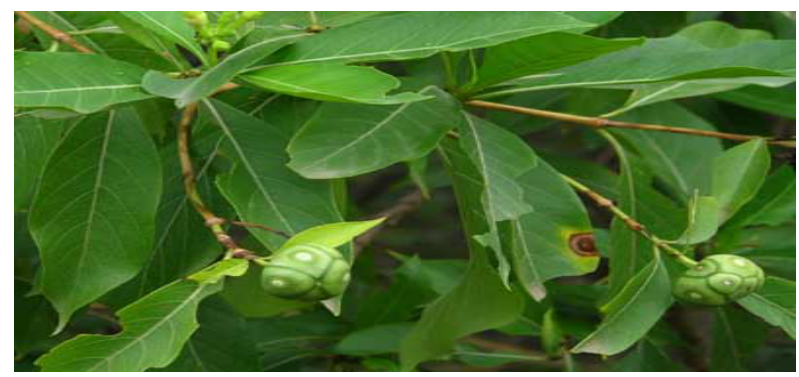

Figure 1: Experimental plant Morinda tinctoria. reaction mixture by observing the colour change of the medium. The AgNps solution thus obtained was purified by repeated centrifugation at $5,000 \mathrm{rpm}$ for 20 minutes. The supernatant was discarded and the pellet was dissolved in double distilled water. The AgNps were confirmed by colour change [12].

Characterization: The produced nanoparticles were subjected to UV-Vis spectroscopy analysis, Atomic Force Microscopy (AFM) analysis and Fourier Transform Infrared Radiation (FTIR) spectroscopy analysis with assistance through Madurai Kamaraj University.

\section{Analysis}

UV-Vis absorbance spectroscopy: The samples used for analysis were diluted with $2 \mathrm{ml}$ of double distilled water and subsequently measured by the UV-Vis spectroscopy at regular time intervals by using a quartz cuvette with water as a reference and the culture were stopped by vaccum filtration [13]. The UV-Vis spectroscopy analysis of silver nanoparticles produced were carried out as a function of bioreduction time at room temperature on ELICO spectrophotometer at a resolution of $1 \mathrm{~nm}$. The UV-Vis spectrometric readings were recorded at a scanning speed of 200-800 $\mathrm{nm}$.

AFM imaging: Surface topology of the formulated AgNps was studied by AFM analysis. AFM studies of AgNps were done by placing a drop of the colloidal solution of AgNps on a cover slip and allowed to dry overnight at room temperature. A thin film of the sample was prepared on a glass slide by dropping $100 \mu \mathrm{L}$ of the sample on the slide and was allowed to dry for 5 minutes. In order to perform AFM analysis, the particles were deposited on a silicon slide and the solvent evaporated. The samples were air-dried and allowed to characterize by atomic force microscopy for its detailed morphology and size. The slides were scanned with the AFM (A100SGS AFM, A.P.E. Research, Italy). The microscope was used in the non-contact mode at a $325 \mathrm{kHz}$ resonance frequency and an approximate $46 \mathrm{~N} / \mathrm{m}$ constant force. The microscope was equipped with a commercial silicon cantilever (NSC15/ AIBS). Image metrology SPIP data analysis software Basic module was used for the AFM analysis.

\section{FTIR spectroscopy}

To remove free biomass residue (or) compound that is not the capping ligand of the nanoparticles, the residue solution of $100 \mathrm{ml}$ after reaction was centrifuged at 5,000 rpm for 10 minutes. The supernatant was again centrifuged at $10,000 \mathrm{rpm}$ for 60 minutes, and the pellet was obtained. The pellet was followed by redispersal of AgNps into $1 \mathrm{ml}$ deionized water. Thereafter, the purified suspension was freeze dried to obtain dried powder. Finally, the dried AgNps were analyzed by FTIR analysis [14].

Larval rearing of A. aegypti: Eggs of Ae. aegypti paper strips were obtained from CRME (ICMR), Madurai, TamilNadu, India. The strips were larvae were floated in enamel tray containing distilled water. They were maintained and reared with yeast powder and dog biscuits in the laboratory. They were allowed to moult upto $3^{\text {rd }}$ instar and were used for the experiment.

Larvicidal bioassay: All experiments were carried out at room temperature. The larvicidal activity was assessed by the standard procedure of WHO [15] with modifications as per the method described by Rahuman et al. [16]. Twenty five $3^{\text {rd }}$ instar larvae of $A e$. aegypti were transferred separately from culture being maintained in the laboratory to the $250 \mathrm{ml}$ beaker containing the $100 \mathrm{ml}$ of desired concentration of plant extracts and AgNps respectively. The control was set up with dechlorinated tap water. The moribund larvae were counted 


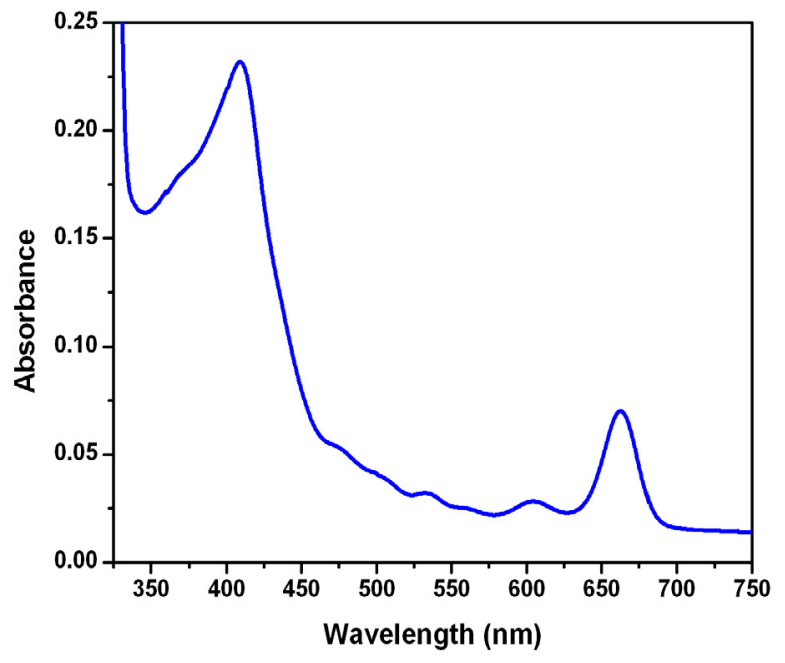

Figure 2: UV-Vis spectra of silver nanoparticles synthesized by treating $M$. tinctoria leaf extract with $1 \mathrm{mM}$ silver nitrate solution.
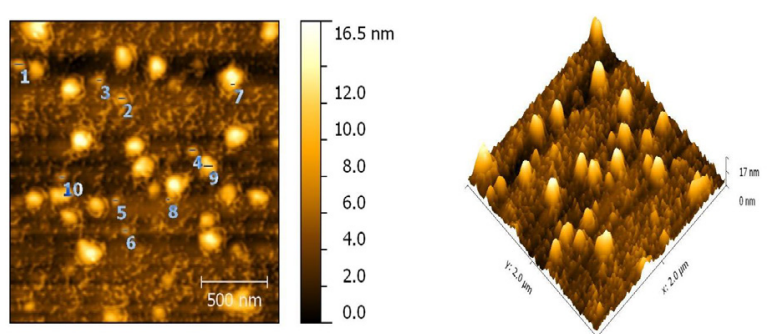

Figure 3: AFM topography of synthesized silver nanoparticles by $M$. tinctoria leaf extract.

after $24 \mathrm{~h}$ of exposure and the percentage mortality was recorded for the average of four replicates. Statistical analysis such as $\mathrm{LC}_{50}$ values, $95 \%$ confidential limit and chi square values were calculated by using EPA Probit analysis programme version 1.5.

\section{Results and Discussion}

The present study demonstrated the formation of the silver nanoparticles by the reduction of the aqueous silver metal ions during exposure to the extract of $M$. tinctoria. The reaction of ions occurred within $1 \mathrm{hr}$ at $37^{\circ} \mathrm{C}$ and appearance of reddish brown colour from colorless solution.

\section{UV-Vis spectroscopy analysis}

AgNps synthesized by using M. tinctoria were formed at $409 \mathrm{~nm}$ with polydispersed (Figure 2). UV-Vis spectroscopy is one of the most widely used techniques for structural characterization of silver nanoparticles [17]. Generally, UV-VIS spectroscopy can be used to examine size and shape of the controlled nanoparticles in aqueous suspense. The results of the UV-VIS absorption showed increasing colour intensity with increased time intervals and this might be due to the production of the silver nanoparticles [18] and the formation of the brownish yellow colour might be due to the excitation of the surface plasmon vibration of the synthesized AgNps [19]. The broadness of the peak is a good indicator of the size of the nanoparticles. As the particle size increases the peak becomes narrower with a decreased bandwidth
[20,21]. In a study by Jain et al., has been reported that the absorption spectra of AgNps were highly symmetric single band absorption with peak at $421 \mathrm{~nm}$ [22].

\section{AFM analysis}

AFM study provides solid evidence of nanoparticles formation and their size and shape of the resultant particles were elucidated (Figures $3 \mathrm{a}$ and $3 \mathrm{~b}$ ). The spherical shaped, crystalline nature of the Ag NPs were obtained at 60-95 nm and showed their topography from leaf extract of $M$. tinctoria and they were found to be highly dispersed and scattered due to its spherical nature in the synthesized medium. The findings were corroborate with spherical nature of AgNps produced using leaf extract of Cissus quadrangularis and Calotropis gigantea and they obtained at 50-60 $\mathrm{nm}$ and 6.3-12.67 $\mathrm{nm}$ ranges in their size [23,24]. Here too the nanoparticles display a rich variety of shape and sizes. Particularly fascinating are the abundance of nano-prisms, nano-rods and nano-trapezoids and the wide variation in the size and shape was indicated in absorption spectra of produced $\mathrm{Ag}$ and $\mathrm{Au}$ nanoparticles at $\sim 20 \mathrm{~nm}$ ranges from black tea leaf extracts [25].

\section{FTIR analysis}

FTIR analysis was carried out to identify the possible interactions between silver and bioactive molecules, which may be responsible for synthesis and stabilization (capping) of silver nanoparticles (Figure 4). The intensed peak $3435 \mathrm{~cm}^{-1}, 2085 \mathrm{~cm}^{-1}, 1639 \mathrm{~cm}^{-1}, 1369 \mathrm{~cm}^{-1}, 1226$ $\mathrm{cm}^{-1}$ and $532 \mathrm{~cm}^{-1}$ indicated the presence of hydroxyl $(\mathrm{OH})$ group, benzene ring, carboxylic $(\mathrm{C}=\mathrm{O})$ group, alkyl halide group respectively. The results of the FTIR used to identify the possible bio molecules responsible for the stabilization of the synthesized silver nanoparticles. The prominent peaks of the FTIR results are showing the correspond values to the amide group (N-H stretching- $3435 \mathrm{~cm}^{-1}$ ), alkane group $\left(\mathrm{CH}-2085 \mathrm{~cm}^{-1}\right)$ alkene (CC- $1639 \mathrm{~cm}^{-1}, 1369 \mathrm{~cm}^{-1}, 1226 \mathrm{~cm}^{-1}$ and $532 \mathrm{~cm}^{-1}$ ) and ether groups (COC-1 031.73). Similar observation also found as flavonoids, triterpenoids and polyphenols [26]. Hence, the terpenoids are proved to have good potential activity to convert the aldehyde groups to carboxylic acids in the metal ions. Further, amide groups are also responsible for the presence of the enzymes and these enzymes are responsible for the reduction synthesis and stabilization of

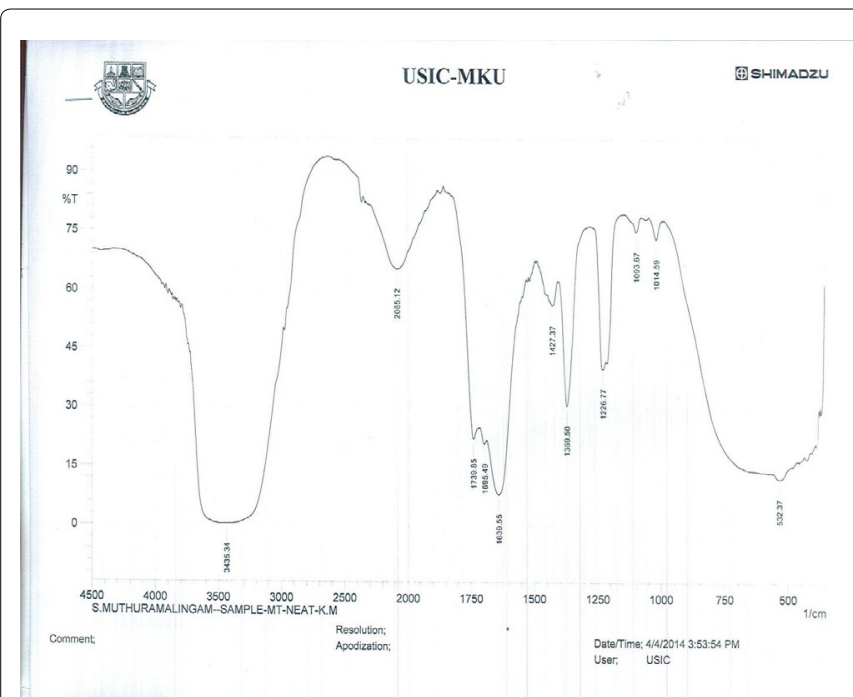

Figure 4: FTIR spectra silver nanoparticles synthesized using M.tinctoria leaf extract with $1 \mathrm{mM}$ silver nitrate solution. 
Citation: Ramesh Kumar K, Nattuthurai, Gopinath P, Mariappan T (2014) Biosynthesis of Silver Nanoparticles from Morinda tinctoria Leaf Extract and their Larvicidal Activity against Aedes aegypti Linnaeus 1762. J Nanomed Nanotechnol 5: 242. doi: 10.4172/2157-7439.1000242

Page 4 of 5

\begin{tabular}{|c|c|c|c|c|c|c|c|}
\hline \multirow{2}{*}{ Extract } & \multirow{2}{*}{ Species } & \multirow{2}{*}{$\mathrm{LC}_{50}$ Value (ppm) } & \multicolumn{2}{|c|}{ 95\% Confidential limit } & \multirow{2}{*}{$\begin{array}{c}\text { Chi-square } \\
x^{2}\end{array}$} & \multirow{2}{*}{ S.E } & \multirow{2}{*}{ Slope } \\
\hline & & & LCL & UCL & & & \\
\hline Leaf & Ae. aegypti & 11.716 & 9.881 & 13.638 & 5.750 & 0.584 & 3.40 \\
\hline AgNps & Ae. aegypti & 3.631 & 3.094 & 4.187 & 5.536 & 0.640 & 4.00 \\
\hline
\end{tabular}

LCL - Lower Confidential Limit, UCL - Upper Confidential Limit

Table 1: Larvicidal activity of leaf extract and synthesized silver nanoparticles of $M$. tinctoria against $A$. aegypti.

the metal ions, further, polyphenols are also proved to have potential reducing agent in the synthesis of the AgNps $[27,28]$.

\section{Larvicidal activity of leaf extracts and synthesized AgNps}

Third instar larvae of Ae. aegypti was treated with biosynthesized silver nanoparticles and the percentage mortality was assessed against various concentrations ranging between $(0.5-7 \mathrm{ppm})$. The $\mathrm{LC}_{50}$ value of synthesized AgNps was $3.631 \mathrm{ppm}$ (Table 1). The low release rate of nanoemulsion with large droplets size that resulted in prolonged mosquito repellent activity compared to the nanoemulsion with small droplets [29].

The acetone extract of $M$. tinctoria was tested for its efficiency against third instar larvae of Ae. aegypti. The larvae were subjected to different concentrations (2-24 ppm) of the leaf extract and 11.716 ppm was recorded as $\mathrm{LC}_{50}$ value (Table 1). Similar studies envisaged that the Indian marine algae extracts possessed potential larvicidal activity [30]. Aqueous (Physiological saline) extract of seed kernel from soap nut Sapindus emarginatus (Sapindaceae) was found to exhibit, a strong antimosquito activity as evident from its ability to inflict $100 \%$ mortality of all the developmental stage of Ae. aegypti [31].

The biosynthesized AgNps from leaf extract of $M$. tinctoria showed potential larvicidal activity against Ae. aegypti larvae. Hence, the larvicidal activity of the AgNps might be due to the denaturation of the sulfur-containing proteins or phosphorous containing compound like DNA that, leads to the denaturation of organelles and enzymes $[32,33]$ and thus reduces the cellular membrane permeability and reduction in ATP synthesis which finally causes the lost of the cellular function and cell death [34]. The size and shape of nanoparticles plays an important role in many of the pharmaceutical/industrial/biological applications. In this regard, the size of the synthesized nanoparticles was identified as $60-95 \mathrm{~nm}$ with various spherical shapes, which falls closer to many of the AgNps produced by other plant materials [35,36].

Today, environmental safety is considered to be most warranted the applicable of AgNps in plant extract and highly appreciable and practical. An insecticide should be ecofriendly nature and acceptable by the community to cause the desire mortality against target organisms. Phytochemical may serve as relatively safe, inexpensive and readily available and several plants are being used in traditional medicines for the mosquito larvicidal activities in many parts of the world.

\section{Acknowledgement}

The authors are grateful to the Principal, management and Head of the Department of PG and Research Dept. of Zoology, Vivekananda College for facilitating to carry out this work. The authors are also indebted to the assistance rendered by the Laboratory staff of the college.

\section{References}

1. Kovendan K, Murugan K, Shanthakumar SP, Vincent S, Hwang JS (2012) Larvicidal activity of Morinda citrifolia L. (Noni) (Family: Rubiaceae) leaf extract against Anopheles stephensi, Culex quinquefasciatus, and Aedes aegypti. Parasitol Res 111: 1481-1490.

2. Hales S, de Wet N, Maindonald J, Woodward A (2002) Potential effect of population and climate changes on global distribution of dengue fever: an empirical model. Lancet 360: 830-834.
3. Maillard M, Marston A, Hostettmann K (1993) Search for molluscicidal and larvicidal agents from plants. In: Balandrin M (ed) Human medicinal agents from plants.

4. Ali MS, Ravikumar S, Beula JM (2012) Bioactivity of seagrass against the dengue fever mosquito Aedes aegypti larvae. Asian Pac J Trop Biomed 2: 570573.

5. Liu N, Xu Q, Zhu F, Zhang L (2006) Pyrethroid resistance in mosquitoes. Insect Sci 13: 159-166.

6. Rahuman AA, Bagavan A, Kamaraj C, Saravanan E, Zahir AA, et al. (2009) Efficacy of larvicidal botanical extracts against Culex quinquefasciatus Say (Diptera: Culicidae). Parasitol Res 104: 1365-1372.

7. Kamaraj C, Bagavan A, Elango G, Zahir AA, Rahuman AA, et al. (2011) Larvicidal potential of medicinal plant extracts against Anopheles subpictus and Culex tritaeniorhynchus. Indian J Med Res 134: 101-106.

8. Shahi M, Hanafi-Bojd AA, Iranshahi M, Vatandoost H, Hanafi-Bojd MY (2010) Larvicidal efficacy of latex and extract of Calotropis procera (Gentianales: Asclepiadaceae) against C. quinquefasciatus and An. stephensi (Diptera: Culicidae). J Vector Borne Dis 47: 185-188.

9. Isman MB (1997) Neem and other Botanical insecticides: Barriers to commercialization. Phytoparasitica 25: 339-344.

10. Shaalan EA, Canyon D, Younes MW, Abdel-Wahab H, Mansour AH (2005) A review of botanical phytochemicals with mosquitocidal potential. Environ Int 31: 1149-1166.

11. Sarah JS, Raji KP, Mohankumar NC, Balagopalan M (2012) Larvicidal potential of biologically synthesized silver nanoparticles against Ae. albopictus. Res $\mathrm{J}$ Recent Sci: 52-56.

12. Satyavani K, Ramanathan T, Gurudeeban S (2011) Plant mediated synthesis of biomedical silver nanoparticles by leaf extract of Citrullus colosynthis. Res $\mathrm{J}$ Nano Technol 1: 95-101.

13. Rajesh WR, Jaya RL, Niranjan SK, Vijay DM, Sahelebrao BK (2009) Phyto synthesis of silver nanoparticles using Gliricidia sepium (Jaeq). Curr Nano Sci 5: 117-122.

14. Vivek M, Kumar PS, Steffi S, Sudha S (2011) Biogenic Silver Nanoparticles by Gelidiella acerosa Extract and their Antifungal Effects. Avicenna J Med Biotechnol 3: 143-148.

15. WHO (1996) Report of the WHO informal consultation on the evaluation on the testing of insecticides.

16. Rahuman AA, Gopalakrishnan G, Ghouse BS, Arumugam S, Himalayan B (2000) Effect of Feronia limonia on mosquito larvae. Fitoterapia 71: 553-555.

17. Sun YP, Atorngitjawat P, Meziani MJ (2001) Preparation of silver nanoparticles via rapid expansion of water in carbon dioxide micromulsion into reductant solution. Lagmuir 17: 5707-5710.

18. Shrivastava S, Dash D (2010) Label-free colorimetric estimation of proteins using nanoparticles of silver. Nano-Micro Lett 2: 164-168.

19. Krishnaraj C, Jagan EG, Rajasekar S, Selvakumar P, Kalaichelvan PT, et al. (2010) Synthesis of silver nanoparticles using Acalypha indica leaf extracts and its antibacterial activity against water borne pathogens. Coll Surf B Biointer 76: 50-56.

20. Petit C, Lixon P, Pileni MP (1993) Insitu synthesis of silver nanocluster in AOT reverse micelles. J Physical Chemistry 97: 12974-12983.

21. Kong H, Jang J (2006) One-step fabrication of silver nanoparticle embedded polymer nanofibers by radical-mediated dispersion polymerization. Chem Commun (Camb): 3010-3012.

22. Jain N, Bhargava A, Majumdar S, Tarafdar JC, Panwar J (2011) Extracellula biosynthesis and characterization of silver nanoparticles using Aspergillus flavus NJP08: A mechanism perspective. Nanoscale 3: 635-641. 
Citation: Ramesh Kumar K, Nattuthurai, Gopinath P, Mariappan T (2014) Biosynthesis of Silver Nanoparticles from Morinda tinctoria Leaf Extract and their Larvicidal Activity against Aedes aegypti Linnaeus 1762. J Nanomed Nanotechnol 5: 242. doi: 10.4172/2157-7439.1000242

Page 5 of 5

23. Sivakama Valli J, Vaseeharan B (2012) Biosynthsis of silver nanoparticles by Cissus quadrangularis extracts. Mater lett 82: 171-173.

24. Vaseeharan B, Clara Gunapoorani S, Lin YC, Chen JC (2012) Green synthesis of silver nanoparticles through Calotropus gigantea leaf extracts and evaluation of antibacterial activity against Vibrio alginolytics. Nanotech Develop 2: 12-16.

25. Begum NA, Mondal S, Basu S, Laskar RA, Mandal D (2009) Biogenic synthesis of Au and Ag nanoparticles using aqueous solutions of Black Tea leaf extracts. Colloids Surf B Biointerfaces 71: 113-118.

26. Nabikhan A, Kandasamy K, Raj A, Alikunhi NM (2010) Synthesis of antimicrobial silver nanoparticles by callus and leaf extracts from saltmarsh plant, Sesuvium portulacastrum L. Colloids Surf B Biointerfaces 79: 488-493.

27. Prasad TN, Elumalai EK (2011) Biofabrication of Ag nanoparticles using Moringa oleifera leaf extract and their antimicrobial activity. Asian Pac J Trop Biomed 1: 439-442.

28. Mukunthan KS, Elumalai EK, Patel TN, Murty VR (2011) Catharanthus roseus: a natural source for the synthesis of silver nanoparticles. Asian Pac J Trop Biomed 1: 270-274.

29. Sakulku U, Nuchuchua O, Uawongyart N, Puttipipatkhachorn S, Soottitantawat A, et al. (2009) Characterization and mosquito repellent activity of Citronella oil nanoemulsion. Int J Pharm 8372: 105-111.

30. Rao DR, Mani TR, Rajendran R, Joseph AS, Gajanana A, et al. (1995) Development of a high level of resistance to Bacillus sphaericus in a field population of Culex quinquefasciatus from Kochi, India. J Am Mosq Control Assoc 11: 1-5.
31. Koodalingam A, Mullainadhan P, Arumugam M (2009) Antimosquito activity of aqueous kernel extract of soapnut Sapindus emarginatus: impact on various developmental stages of three vector mosquito species and nontarget aquatic insects. Parasitol Res 105: 1425-1434.

32. Sondi I, Salopek-Sondi B (2004) Silver nanoparticles as antimicrobial agent: a case study on E. coli as a model for Gram-negative bacteria. J Colloid Interface Sci 275: 177-182.

33. Choi O, Deng KK, Kim NJ, Ross L Jr, Surampalli RY, et al. (2008) The inhibitory effects of silver nanoparticles, silver ions, and silver chloride colloids on microbial growth. Water Res 42: 3066-3074.

34. Sap-iam N, Homklinchan C, Larpudomlert R, Waris-noicharoen W Sereemaspun A, et al. (2010) UV irra- diation induced silver nanoparticles as mosquito larvicides. J Appl Sci 10: 3132-3136.

35. Tripathi A, Chandrasekaran N, Raichur AM, Mukherjee A (2009) Antibacterial applications of silver nanoparticles synthesized by aqueous extract of Azadirachta indica (Neem) leaves. J Biomed Nanotechnol 5: 93-98.

36. Vivekanandhan S, Misra M, Mohanty AK (2009) Biological synthesis of silve nanoparticles using Glycine max (soybean) leaf extract: an investigation on different soybean varieties. J Nanosci Nanotechnol 9: 6828-6833. 